\title{
JAKUB GOŁĘBIEWSKI
}

Instytut Etnologii UMK

\section{Bomba w turbanie}

30 września 2005 r. w duńskim dzienniku "Jyllands-Posten” w artykule 3 Twarz Mahometa ukazało się dwanaście karykatur Mahometa1 ${ }^{1}$ które wywołały burzliwe reakcje w krajach muzułmańskich, głównie arabskich. W efekcie w lutym 2006 r. zaatakowano lub podpalono kilkanaście placówek dyplomatycznych Danii, Norwegii oraz innych państw europejskich. Tysiące protestujących muzułmanów musiało się poczuć dotkniętych do żywego, choć ciekawym jest, iż protesty, a wraz z nimi podpalenia, nastały w kilkanaście tygodni po publikacji. Duński premier określił ów konflikt najpoważniejszym w powojennych dziejach Królestwa Danii. Poniższy tekst stawia sobie za cel opisać semantyczną zawartość opublikowanych wizerunków, a następnie omówić różne traktowanie obrazu w ogóle w obrębie dwu kręgów kulturowych, które na tym tle weszły w ostry konflikt.

Kåre Bluitgen, duński pisarz, autor edukacyjnej książki dla dzieci na temat islamu, żalił się, że ilustratorzy odmawiali mu narysowania Mahometa, albowiem jego obrazowanie jest zakazane przez Koran i mogłoby im przysporzyć kłopotów. Rok wcześniej holenderski reżyser Theo van Gogh, krytykujący świat islamski został zamordowany przez Holendra marokańskiego pochodzenia. W następstwie dziennik "Jyllands-Posten" postanowił wystąpić przeciwko autocenzurze prasy i narzucaniu jej dogmatycznych norm religijnych. Postanowiono zamieścić w tej sprawie artykuł ilustrowany

\footnotetext{
${ }^{1}$ Por. Karykatury Mahometa na stronie Assyrian International News Agency, dostępne: http://www.aina.org/releases/20060201143237.htm [15.06.2007].
} 
karykaturami Mahometa. O naszkicowanie karykatur zwrócono się do czterdziestu rysowników. Jedynie dwunastu nadesłało swoje prace ${ }^{2}$.

Na wstępie zaznaczę, że karykatura jest obiektem wyjątkowo wdzięcznym do analizy ikonosfery, albowiem jej forma wymusza posługiwanie się schematycznym obrazem rzeczywistości. Karykatura sugeruje odbiorcy występowanie określonych cech u karykaturowanej osoby w taki sposób, jakby koniecznie i zawsze współwystępowały one u niej w rzeczywistości. Im bardziej to uproszczenie czy „spłaszczenie” wizerunku przedstawianej osoby jest zaskakujące, tym lepiej rysownikowi udaje się zamierzony dowcip, choć oczywiście jego kunszt oceniamy również poprzez umiejętny dobór tematu, opanowanie warsztatu itd. W pewnych określonych warunkach, gdy temat karykatury jest już intensywnie eksploatowany, karykatura staje się rodzajem zabawnej ikony, gdzie wprawdzie chodzi o zaskoczenie odbiorcy, ale sama karykaturowana postać przedstawiana jest zgodnie z wyrobionym kanonem. Kiedy pojawia się dany temat, od razu możemy spodziewać się towarzystwa kolejnych tematów i cech karykaturowanej osoby, do których współwystępowania przyzwyczaiła nas ikona. Takimi ikonami karykatury były swojego czasu „Zapluty karzeł reakcji na łańcuchu amerykańskiego imperializmu”, „Żyd wyzyskiwacz”, a ostatnio George W. Bush, którego karykaturzyści amerykańscy tylko z rzadka przedstawiają bez teksańskiego kapelusza i twarzy debila (w znaczeniu terminu medycznego).

Podobnie, stanąwszy przed koniecznością zobrazowania Mahometa, stereotypizacją posłużyli się rysujący dla "Jyllands-Posten”. Ponieważ, w przeciwieństwie do chrześcijaństwa czy buddyzmu, w islamie nie istnieje tradycja przedstawiania Proroka, do której można by się odwołać, ilustratorzy musieli wynaleźć jakieś atrybuty tej „niewidzianej” postaci, które jednoznacznie wskazywałyby na Mahometa. Zadanie tym trudniejsze, że w ambitnej karykaturze podpisywanie rysunków nie wchodzi w grę. Jak się okazało, strategia obrana przez większość rysowników dała możliwość dwojakiego czytania karykatur. Przedstawiana postać może zatem być Mahometem lub po prostu muzułmaninem czy jeszcze ogólniej Arabem. Dzieje się tak, ponieważ, zgodnie z zasygnalizowaną logiką karykatury, dochodzi tu do zlania się przedstawianego Mahometa z muzułmanami, których społeczne normy są właściwym celem karykatury. Rysunki, o których mowa znane są jako „karykatury Mahometa”. Strona z artykułem otoczonym przez karykatury nosi tytuł Twarz Mahometa, lecz fakt, że wśród dwunastu obrazków tylko połowa Go przedstawia, sugeruje, że tytuł ten należy traktować przenośnie jako

Zob. Jyllands-Posten Muhammad cartoons controversy, dostępne: http://en.wikipedia.org/wiki/ Jyllands-Posten_Muhammad_cartoons_controversy [15.06.2007]. 
„oblicza Mahometa” czy raczej „oblicza islamu”. W rzeczy samej, redakcja duńskiej gazety deklarowała swój sprzeciw wobec narzucania prasie dogmatycznych norm religijnych. Motywem publikacji nie było ośmieszenie religijnego przywódcy, lecz skrytykowanie przywiązania muzułmanów do norm religijnych. Taka była intencja redakcji. Jak jednak w praktyce krytyka ta została zakomunikowana? Jakimi posłużono się środkami wyrazu?

Sześć z dwunastu rysunków przedstawia brodatego mężczyznę $z$ turbanem na głowie, kombinowanym $z$ tuniką i sandałami. Tylko jeden rysownik posłużył się ogólnoislamskim symbolem przybierającego półksiężyca i gwiazdy; zresztą i w tym przypadku wplótł on go w wizerunek brodacza w turbanie. Inne motywy, które zawarte są w karykaturach to: religijna legitymizacja przemocy i terroryzm (po trzy rysunki), indoktrynacja religijno-polityczna muzułmanów (trzy rysunki), opresja kobiet (trzy rysunki), imigracja do Europy (jeden rysunek), czterokrotnie zaś rysownicy odnieśli się do spodziewanej nerwowej reakcji muzułmanów na przedstawione karykatury.

Pomimo tego, że turban jest symbolem religijnym nie tylko dla muzułmanów, a przede wszystkim dla Sikhów, oraz że muzułmanie Azji Południowo-Wschodniej oraz Czarnej Afryki rzadziej go wiążą, posłużył on jako identyfikator całego świata islamskiego. W połączeniu z brodą, kojarzy się z wizerunkiem, jaki w Europie przypisujemy „Arabom”. Użycie cudzysłowu tłumaczy się faktem, że często za Arabów bierze się również noszących turbany Persów, Afganów czy Pakistańczyków. To ci brodaci, a zwłaszcza wyposażeni w turbany, „Arabowie” w popularnej świadomości człowieka Zachodu reprezentują muzułmanina. Kiedy mamy do czynienia z muzułmanami nie pasującymi do tego wizerunku, na przykład Albańczykami, Ujgurami, Somalijczykami, czy Indonezyjczykami skłonni jesteśmy identyfikować wysuwając na pierwszy plan ich etniczno-kulturową tożsamość. Nawet wówczas gdy oni sami chcą być widziani po prostu jako muzułmanie.

Orientalną tonację karykatur wzmacniają dodatkowo azjatyckie stroje - salwar-kameez ${ }^{3}$ przedstawianego Mahometa/muzułmanina. Wyobrażenia te są tym bardziej egzotyczne, że wszelkie bojowe i terrorystyczne akcesoria nie są współczesne, pochodzą z dawnych czasów: arabski XVII-wieczny miecz saij ${ }^{4}$ oraz kulista bomba z lontem. Inna sceneria to orientalny pałac à la Szeherezada, pustynia i wielbłąd. Ciekawe czy bojownik bardziej „oswojony”, tak jak jest ETA dla Hiszpanów, IRA dla Brytyjczyków czy OWP dla Izraelczyków też byłby tak wyobrażany? Czy w przypadku grupy egzystującej blisko

\footnotetext{
Zob. Salwar kameez, dostępne: http://en.wikipedia.org/wiki/Salwar_kameez [15.06.2007].

${ }^{4}$ Zob. Saif, dostępne: http://en.wikipedia.org/wiki/Saif [15.06.2007].
} 
i znanej z codziennych kontaktów, też posłużono by się archaicznymi atrybutami? Wydaje się, że przedstawianie na przykład Irlandczyków w brytyjskiej prasie odwołując się do, dajmy na to, tradycyjnego niegdyś na Irlandii pasterstwa, byłoby nieczytelnym anachronizmem. Z pewnością archaiczna stylizacja sygnalizuje domniemaną „ewolucyjną” wyższość kultury zachodniej nad arabską. Karykatury (ich treść omówiona zostanie w dalszym ciągu) przedstawiające muzułmanina (użycie liczby pojedynczej ma podkreślać, że tematem analizy jest ikona muzułmanina/Araba) jako zamachowca czynią nam go obcym, bo wrogim, ale jest on również obcy, bo umieszczany w odległej kulturowo oraz czasowo przestrzeni.

Z tej konwencji wyłamuje się ciekawa karykatura, przedstawiająca europejskiego reprezentanta islamu. Jest to siódmoklasista kopenhaskiej szkoły. Ciemna karnacja i imię Mohammed wskazują afrykańskie korzenie jego rodziców lub dziadków. Tym razem jest on ubrany w sposób typowy dla nastolatka. Szerokie spodnie i nogawki opadające poniżej podeszew butów. Nosi on koszulkę futbolową z barwami kopenhaskiej drużyny „Frem” z napisem „przyszłość” - słowem, które nabierze złowieszczo paradoksalnego wydźwięku w kilka tygodni później, kiedy spłonie duńska ambasada. Na tablicy szkolnej powieszonej za nim, wypisane jest po persku zdanie: „Dziennikarze Jyllands-Posten to banda reakcyjnych prowokatorów”. Znajomość ideologicznej retoryki oraz arabskiego pisma karze przypuszczać, że wyniósł on te wiadomości z domu lub sobotniej szkoły koranicznej. $O$ ile ten obraz budzi mniej strachu niż wizerunki zamaskowanych uzbrojonych mężczyzn, o tyle ewokuje on niechęć do imigrantów, którzy w oczach wielu obywateli Europy są gośćmi korzystającymi z hojnej opieki otwartego państwa, jednocześnie mając czelność występować przeciw tej otwartości. Podsumowując, za czynniki wywołujące skojarzenia $\mathrm{z}$ islamem posłużyły tutaj cechy antropologiczne (czarne włosy), arabskie pismo oraz imię chłopca, które nota bene jest tym samym, co imię Proroka.

Zgodnie z wymową artykułu duńskiego dziennika, kilka rysunków wytyka przywiązanie do ideologii Świętej Wojny. Pierwsza z karykatur ilustruje Mahometa/muzułmanina stojącego $\mathrm{w}$ prostej tunice $\mathrm{z}$ rękoma nabożnie złożonymi na piersi i z błyszczącą aureolą nad głową. Ma ona formę diablich rogów. Ten obraz zdaje się nam dawać do zrozumienia, że muzułmanin to typ skrywający pod płaszczykiem nabożności nieczyste intencje. Inny obrazek nie pozostawia wątpliwości, jakiego rodzaju miałyby to być intencje. Przedstawia on głowę brodacza $\mathrm{w}$ turbanie $\mathrm{w}$ kształcie bomby $\mathrm{z}$ odpalonym lontem, na której wygrawerowane jest muzułmańskie Credo shahadah ${ }^{5}$. Połą-

${ }^{5}$ Zob. Shahadah, dostępne: http://en.wikipedia.org/wiki/Shahadah [15.06.2007]. 
czenie fanatycznej religijności z bezwzględnym terroryzmem jest w tym rysunku aż nadto oczywiste. Karykatury te odzwierciedlają schematyczne wyobrażenia, jakie Europejczycy często chowają odnośnie muzułmanów. Uosabia je mianowicie mężczyzna, rzadko kobieta, bo te, podobnie jak „my” niewierni, są przez nich również nękane, muzułmanin, gotowy na wszystko w obronie honoru swej religii i swego proroka. By sparafrazować powyższą karykaturę, jest on skłonny wysadzić własną głowę.

Jednak ci samobójcy nie są tak prostolinijni, by wysadzać się bez żadnej gratyfikacji. Kolejna karykatura przedstawia ciągnącą do Nieba kolejkę dusz zamachowców - zdetonowanych już żywych bomb. Przybywają po przyobiecane każdemu siedemdziesiąt dwie dziewice. Obraz sugeruje, że muzułmanin to człowiek kompletnie zaimpregnowany przeciwko idei nadrzędnej wartości ludzkiego życia. Trzeba powiedzieć, że wybór tej charakterystyki muzułmanina jest szczególnie dogodnym środkiem, by powiększyć kulturową granicę między nim a Europejczykiem.

Po pierwsze, potępiamy zamachowców nie tylko jako ludzi uderzających w nas, Europejczyków, ale w ogóle odrzucamy terrorystyczną metodę walki bez względu na to, w czyim toczona jest interesie. Ludzie posługujący się terroryzmem wydają nam się nieuczciwi i okrutni, ponieważ na swe ofiary świadomie wybierają przypadkowych ludzi. Europejski etos zaś ustanawia cenę ludzkiego życia bardzo wysoko. Karykatura ukazująca muzułmanów chwytających za broń w reakcji na publikację rysunku, który dla nas, bez względu na treść, jest tylko kawałkiem papieru, wydaje nam się reakcją, mówiąc oględnie, wyolbrzymioną.

Po drugie, wydaje nam się, że tylko człowiek indoktrynowany nachalną ideologią może poświęcić swe życie, by odebrać życie komuś innemu. Europa mądra doświadczeniem Świętej Inkwizycji, oraz totalitaryzmów XX wieku, a do tego w większości laicka i materialistyczna wyjątkowo brzydzi się ideologiczną indoktrynacją. Ludzi podporządkowanych ideologii, czy to religijnej czy społeczno-politycznej, uważa się za niedorosłych i naiwnych. Są to oczywiście sądy wypowiadane z perspektywy, wedle której europejskość rozumiana jest jako pewna pluralistyczna i liberalna formacja intelektualna, nie zaś jako nazwa jakiegokolwiek prądu intelektualnego wywodzącego się geograficznie z Europy.

Choć, jak powiedziałem, humanizm europejski brzydzi się ideologią, to ceni idealizm, jako działanie na rzecz wspólnoty. Idea religijna jednak jest postrzegana jako idea abstrakcyjna. Z europejskiego punktu widzenia jej bojownicy nie walczą o poprawę bytu swych współwyznawców, ani dla dobra jakiejkolwiek grupy ludzi. Deklarują oni walkę przeciw jednemu słowu „karykatura”, w obronie innego - „Mahomet”. Taką postawę ukazuje 
karykatura mężczyzn, którzy z bronią w ręku biegną spacyfikować publicystów „Jyllands-Posten”. Inna, wcześniej wspomnianej kolejki samobójców do Nieba, którzy chcą czerpać z niebieskich haremów, obliczona jest na wzbudzenie szczególnej odrazy. Tu mający w pogardzie ludzkie życie zamachowcy, w obronie abstrakcyjnej idei, czynią zło, by móc pławić się w przyjemnościach, których źródłem jest przedmiotowe traktowanie kobiet; coś na punkcie czego zachodnie społeczeństwa są również drażliwe, mimo że deklarowane równouprawnienie nie zawsze jest rzeczywistością europejskiego życia. Ale jak to na ogół bywa, nasze wady szczególnie irytują nas u innych, zwłaszcza gdy są otwarcie deklarowane, a to właśnie jest treścią mitu o niebiańskiej nagrodzie dla poległych za wiarę.

Nim omówiony zostanie wątek kobiecy, należy zaznaczyć, że rozpowszechniony na Zachodzie mit nagrody w postaci siedemdziesięciu dwóch dziewic czekających na bezwarunkowo trafiających do raju męczenników dżihadu, jest błędny. Otóż istota, którą tłumaczymy jako „dziewicę” jest zgodnie z literą Koranu istotą „cnotliwą" houri', czy też aniołem i obcowanie $\mathrm{z}$ nią po śmierci niesłusznie kojarzy się nam z wieczną rozpustą i męską dominacją nad kobietą. Niemniej jednak, to właśnie do spopularyzowanej formy tego mitu odnosi się opublikowana karykatura i tak należy ją czytać.

Jak już zostało powiedziane, na trzech ilustracjach pojawia się motyw nierównego traktowania kobiet. Prócz wyżej nadmienionej karykatury motyw ten pojawia się na rysunku, którego motywem centralnym jest zbrojny mąż. Jego oczy przysłania czarny prostokąt, taki jaki umieszczają stacje telewizyjne na oczach podsądnych. Za mężczyzną stoją dwie kobiety. Ich czarne szaty odsłaniają tylko oczy. Czarny prostokąt pasuje rozmiarem do szparki, którą żeńskie szaty pozostawiają na twarz. Wygląda jakby był z nich wycięty. Czy mamy myśleć, że gdyby muzułmański terrorysta nie potrzebował kawałka materiału na zamaskowanie twarzy, strój muzułmanek nie miałby żadnych otworów? Zwróćmy uwagę na choreografię planów na tym rysunku. Postać męska widnieje centralnie. Kobiety przedstawia się tu po bokach, ale za jego plecami. Dodatkowo, z powodu ich stroju, nic nie odróżnia jednej od drugiej. Kobieta to drugi plan ludzkiej aktywności czy też może jej brak. Brak cech szczególnych, cień mężczyzny, pasywność, istota uciemiężona i ubezwłasnowolniona. Myślę, że zaprezentowana ikona kobiety poddanej koranicznemu prawu dobrze wpasowuje w to, co i tak już wydaje się nam, że o niej wiemy.

Zauważmy, że kiedy karykatury lub inny tekst zachodniej kultury ewokuje islamskie „zagrożenie”, uosabia je niemal wyłącznie w męskiej po-

6 Zob. Houri, dostępne: http://en.wikipedia.org/wiki/Houri [15.06.2007]. 
staci. Nie jest przedmiotem tego artykułu stwierdzać, na ile jest to obraz prawdziwy. Jednak z dużą dozą prawdopodobieństwa możemy stwierdzić, że w świecie islamskim nie brakuje kobiet, które popierają terroryzm i walkę z cywilizacją Zachodu. Mimo to, figura kobiety nie pojawia się często jako nośnik tych wrogich nam idei. W muzułmance wolimy widzieć sojusznika, a w każdym razie współcierpiącą z nami z rąk fanatyków. To wyobrażenie dobrze pokazuje inna karykatura. Widać na niej obrys profili pięciu głów przykrytych przez chustki. Obrazek wykonany jest najprostszą techniką, a pięciu profili nic nie odróżnia od siebie. W miejscu twarzy widnieją Gwiazda Dawida oraz Półksiężyc. Domyślam się, że żydowski symbol wskazuje, że judaistyczna ortodoksja z punktu widzenia rysownika traktuje kobietę równie przedmiotowo, co islam. $\mathrm{W}$ przeciwieństwie do dwu poprzednich, ta karykatura odnosi się wyłącznie do motywu opresji kobiet. Zawarta tu krytyka jest chyba najbardziej uniwersalna. Nie potępia dogmatycznego przywiązania do ideologii jako cechy wyłącznie muzułmańskiej, czy arabskiej. Odwrotnie, niczym dobry pedagog rysownik ów karci po równo dwu śmiertelnych wrogów: Arabów i Żydów.

Ostatnią klasę rysunków stanowią te, które zawczasu naigrywają się z przewidywanej nerwowej reakcji muzułmańskiego świata na karykaturowanie Mahometa. Mamy tu rysownika ukradkiem rysującego w ciemnym pokoju postać Mahometa. Artysta ogląda się nerwowo w obawie, czy ktoś go nie spostrzeże. Druga ilustracja, o której już wspominałem w innym kontekście przedstawia władcę orientalnego pałacu, który uspokaja swych gwardzistów chwytających za broń. Trzymając w ręku gazetę, mówi im, że to „tylko rysunek niewiernego Duńczyka”. Ostatni rysunek obrazuje dziennikarza i pisarza Kåre Bluitgena, który stał się pretekstem do publikacji artykułu oraz karykatur w „Jyllands-Posten”. Trzyma on w ręku szkic postaci Mahometa. Sam również nosi turban, w którym ląduje spadająca z góry pomarańcza. „Pomarańcza w turbanie” to duńskie wyrażenie, które można przetłumaczyć: „trafiło mu się jak ślepej kurze ziarnko”" Na pomarańczy napis „publicity stunt” oznaczający prowokacyjne działania mające na celu przyciągnięcie publicznej uwagi. Karykatura sugeruje, że publikacja wywoła burzę, a jej cichym beneficjentem będzie Kåre Bluitgen.

Dlaczego karykatury tak rozjątrzyły muzułmanów? Kiedy ogląda się w telewizji ludzi, którzy z wściekłością na twarzy dewastują ambasadę, chciałoby się wykrzyknąć: „Przestańcie! Opamiętajcie się! To tylko karykatura!". Zgodnie z europejską tradycją dyplomatyczną atak na placówkę dyplomatyczną danego państwa jest równoznaczny z wypowiedzeniem mu

\footnotetext{
${ }_{7}$ Zob. Jyllands-Posten Muhammad cartoons controversy, dz.cyt.
} 
wojny. Wobec tego historia z karykaturami okazuje się absurdalnie paradoksalna, albowiem wyśmiewane i dosłownie zilustrowane w karykaturach przywiązanie muzułmanów do zasad i ideologii religijnej następnie materializuje się na naszych oczach. Karykatura staje się rzeczywistością. Czy karykatury okazały się prorocze, gdyż tak bezwstydnie zaatakowały symbole drogie muzułmanom?

Wydaje się, że przede wszystkim obnażyły one status i wage, jaką obraz posiada w kulturze muzułmańskiej. Z punktu widzenia duńskich publicystów reagujący agresją muzułmanie zachowują się w przewidziany sposób, choć rozmach odwetu przekroczył chyba oczekiwania. Karykaturzyści mogą powiedzieć sobie $\mathrm{w}$ duchu, iż ich karykatury były udane, albowiem celnie ukazały muzułmański fanatyzm, co on sam naocznie potwierdził. Biorąc pod uwagę, że publikacja ośmieszających materiałów nie stanowi w europejskiej prasie problemu tak długo, jak nie podaje się w nich informacji kłamliwych, to pojęcie szkody nie może odnosić się do omawianego przypadku publikacji. W kulturze europejskiej szkoda jest rozumiana przede wszystkim jako uszkodzenie fizyczne lub utrata dóbr, względnie pozbawienie wolności. Reasumując ten punkt widzenia: opublikowano dobre karykatury, którym nie można by zarzucić intencji kłamliwego oszczerstwa.

Jeżeli spróbować przyjąć perspektywę protestujących uczniów Mahometa, to zapewne powiedzą oni, że przecież tylko się bronią, a wojnę wywołali karykaturzyści znieważając ich Proroka, wiarę, oraz ich samych. Reprezentują oni światopogląd oparty na zasadzie honoru podobny temu, który charakteryzował kulturę rycerską średniowiecznej Europy. Zgodnie z tym światopoglądem nie tyle samo uszkodzenie fizyczne czy materialne jest problematyczne, co wynikająca z niego ujma na honorze. Dlatego, obraza symboliczna (słowo, rysunek) nie różni się zasadniczo od napaści. Tym samym, napaść odwetowa wydaje się stosowną odpłatą za zniewagę.

Widać stąd, że konfrontacja dwu światopoglądów, reprezentowanych przez karykaturzystów z jednej strony i podpalaczy z drugiej, musi się zakończyć katastrofalnie. Porozumienie nie jest możliwe, ponieważ dla pierwszych działanie symboliczne (rysunek) jest próbą opisu, mniej lub bardziej artystyczną, zastanej rzeczywistość; dla drugich jest jej motorem, działaniem, które domaga się stosownego „od-działania”. To, co dla jednych jest skutkiem, drugim wydaje się przyczyną. 


\section{A bomb in a turban}

An article entitled A Bomb in a Turban reflects on the reasons of the violent reaction upon the publication of the Mahomet's caricatures in the Danish journal Jyllands-Posten which took place on $30^{\text {th }}$ September 2005.

Firstly, the text analyses the means of expression typical for the caricature which serves as a background for the analysis of the differences of attitudes towards the role of images within the European and the Muslim cultures. Whereas reactions of those issued from the latter show that an image is not a mere sign of reality but an act ample to create it, according to the former one symbolical representations of reality such as words or images are not subdued to the causal relation typical for the realm of deeds. This sort of analysis allows to characterise an idea being so praised in the West - the notion of freedom of speech as liberation of words and images from the impact they are supposed to exert on reality according to the interpretative patterns of cultures based on religious attitudes towards symbols. The anthropological analysis of the role played by the images in the cultures reveals the possible difficulties in the process of intercultural or political dialogue of these two sides.

Taking the dozen of Danish caricatures of the Mahomet into consideration, the text analyses a set of stereotypes, well established in western civilisation. Main points of the authors' concentration were the questions of appearance - the usage of Islamic symbols, clothes and beard was common. Apart from these signs, violence, terror and women's discrimination are considered as characterising Islam. Despite the Arabic world's complexity, these signs were used to characterize it as an entirety. Moreover, the symbols referring mostly to the past do not concern this culture in its modern dimension.

A confrontation, being the result of the publication of caricatures, cannot be commented only as a reaction to a diplomatic scandal, but also as a defense against an attack aimed at a depreciation of the whole culture. 